\title{
Studies on recycled waste glass powder as binder in concrete
}

\author{
Z.KALAKADA and J.H. DOH*, \\ School of Engineering and Built Environment, Griffith University, QLD 4222, Australia \\ Emails: zameer.kalakada@griffithuni.edu.au,j.doh@griffith.edu.au \\ *Corresponding author
}

\begin{abstract}
The present study deals with the experimental investigation on recycled waste Glass Powder (GP) as a pozzolanic cement. Two particle sizes of $75 \mu \mathrm{m}$ and $150 \mu \mathrm{m}$ were used for the current study. The considered GP replacement levels were $0 \%, 20 \%, 40 \%, 60 \%$ and $80 \%$ by weight of cement and workability, density, compressive and tensile strengths were investigated. Test results show that GP as a partial cement replacement has proven feasible for low strength and light weight applications. In addition, GP can be used in places where there is higher demand for workability. Further research into hardening over longer periods and low strength applications, GP concrete could become a sustainable option for industry.
\end{abstract}

Keywords: glass powder; cement replacement; pozzolanic behavior; Compressive strength

\section{INTRODUCTION}

Concrete is one of the most used material in the world, global production rates are rising annually to meet the ever increasing demand. Since cement is the main ingredient in concrete, it is manufactured in enormous quantities. It is estimated that around 85.9 million metric tons of cement is produced in United states alone in comparison to a staggering 4,200 million metric tons worldwide (US Geological Survey, 2017). Gopalakrishnan and Govindarajan (2011) suggested replacing cement with either a solid waste material or industrial by-product as a practical solution for decreasing the Portland cement consumption thereby, reducing the environmental and energy impacts associated with the concrete production. Use of industrial by-products like fly ash from coal combustion, or silica fume from silicon and ferrosilicon alloy production, or blast furnace slag from pig iron production, as cement substitution represents a value-added methodology to address the environmental issues. Hence, there is an increasing demand in utilizing the recycled materials in the construction industry for promoting sustainability and green construction (Arulrajah et al., 2015; Liu et al., 2015; Lopez-Gayarre et al., 2015; Lotfi et al., 2015; Shang et al., 2015; Silva et al., 2015).

In recent years, use of recycled material such as waste glass has received an augmented attention in the concrete industry (Wang et al., 2009; Jain and Neithalath, 2010; Nassar and Soroushian, 2012). At first, waste glass was used as an aggregate replacement in concrete and it was observed that the mechanical and durability properties of the modified concrete were degraded due to the increased potential of Alkali-Silica Reaction (ASR) (Etris et al., 1974; Topcu and Canbaz, 2004; Saccani and Bignozzi, 2010). The main reason for this deterioration 
was due to high percentage of silica in glass cullets which increased the chances of ASR in the concrete. Taha and Nounu (2008) explained that ASR is a deleterious expansion occurring in concrete due to the reaction between siliceous minerals present in aggregate and the alkaline pore solution in concrete. Later, Investigations have shown that ASR occurrence in concrete is dependent on the particle size distribution of glass used, as the particle size decreases the ASR probability reduces (Shao et al., 2000; Shayan and Xu, 2004). The suppressive effect of glass powders on the ASR expansion in concrete was due to the pozzolanic characteristic of glass powder, similar to other pozzolanic materials such as fly ash, silica fume and metakaolin (Duchesne and Berube, 1994; Ramlochan et al., 2000). These results, motivated the use of recycled glass powder with microscopic particle size distribution as cement replacement. There are multiple benefits of using recycled glass powder as cement replacement: firstly, using a waste material would reduce the load on the landfills, secondly, the total cost would be less as a recycled waste glass powder is replacing the costly cement and finally, the use of recycled glass powder would lead to an sustainable construction since decreasing the cement manufacturing.

Experimental investigations have reported that glass when grinded to about $300 \mu \mathrm{m}$ showed negligible ASR and these findings are in agreement with the maximum particle size of $300 \mu \mathrm{m}$ for ASR occurrence (Shayan and Xu, 2004; Farshad et al., 2010; Du and Tan, 2013; Du and Tan, 2014). Mehta (2002) stated that the glass particles start to behave as a pozzolanic material at approximately below $300 \mu \mathrm{m}$ and when the fineness is reduced to about $100 \mu \mathrm{m}$ the pozzolanicity of the glass exceeds that of fly ash at low cement replacement levels and after curing of 90 days. The pozzolanic property of glass increases with the fineness of the glass, as the particle size distribution reduces the pozzolanic ability of the glass increases. Studies as early as 2000, have been reported in the literature pertaining to the GP as cement replacement and the size of the glass particle used ranged from 0-150 $\mu \mathrm{m}$ (Shao et al., 2000). Of late, the researchers concentrated on finer glass particle size ranging from $0-100 \mu \mathrm{m}$ and the maximum percentage of cement replacement is $60 \%$ (Du and Tan, 2015; Kamali and Ghahremaninezhad, 2016; Omran and Tagnit-Hamou, 2016; Du and Tan, 2017). There is no consensus about the ideal cement replacement percentage, as the performance of the glass powder concrete is dependent on various factors including: the particle size distribution and chemical composition of the glass.

In this paper, an experimental investigation into the effect of two glass powders of different fineness on workability, density, compressive and tensile strength of cementitious materials is presented and the performance of these glass powders is compared with a reference mix made with a conventional Portland cement. The glass powders examined in this paper had different fineness, hence allowed investigating the dependence of cementitious material behaviour on the size of the glass powders. As stated in the previous section, the substitution content of cement by GP is limited to $60 \%$, the present experimental work consists of replacing higher volume of GP $(>60 \%)$ as cement replacement in order to check the suitability of GP as a binder by itself rather than a cement replacement. 


\section{EXPERIMENTAL PROGRAM}

\subsection{MATERIALS}

The cement used in this project was general purpose cement which complies with all the regulations and requirements highlighted in AS 3972 for general purpose and blended cement. Glass powder used in the current study was obtained from a recycling centre. Recycled glass powder was obtained by crushing waste glass bottles (such as liquor bottles and soft drink bottles) which were obtained from the local landfill site in the city of Brisbane, Qld, Australia. Cone crusher was used to grind the glass powders to the desired fineness. Two types of glass powders, GP1 (fine glass powder - 85\%<75 $\mu \mathrm{m}$ ) and GP2 (coarse glass powder - $95 \%<150$ $\mu \mathrm{m})$ were used as a high volume binder replacement in the present project. Fine aggregate passing $4.75 \mathrm{~mm}$ sieve was used in the preparation of the mixtures with a specific gravity of 2.69 , water absorption of $1.89 \%$ and fineness modulus of 2.78 .

\subsection{DESIGN}

Glass powders, GP1 $(<75 \mu \mathrm{m})$ and GP2 $(<150 \mu \mathrm{m})$ were used as high volume cement substitution (up to $80 \%$ ), unlike previous studies in which the replacement level of GP was limited to $60 \%$. A constant water to cementitious material ratio of 0.4 was applied, binder and fine aggregate content used in the mixes were fixed at $600 \mathrm{~kg} / \mathrm{m}^{3}$ and $630 \mathrm{~kg} / \mathrm{m}^{3}$ respectively. GP1 was used as cement replacement at $20 \%, 40 \%, 60 \%$ and $80 \%$ by mass. Since, the $80 \%$ substitution didn't yield acceptable outcome the replacement of GP2 was limited to $60 \%$. The mix with $0 \%$ GP is considered as a reference mix (REF) to compare the performance of the glass powders. Mix design used in the experiment is shown in Table 1.

Table 1 Mix proportioning corresponding to a volume of $1 \mathrm{~m}^{3}$ of concrete

\begin{tabular}{|c|c|c|c|c|c|c|}
\hline $\begin{array}{c}\text { Mix } \\
\text { Design }\end{array}$ & $\begin{array}{c}\text { Cement } \\
(\mathrm{kg})\end{array}$ & $\begin{array}{c}\text { GP1 }(<75 \mu \mathrm{m}) \\
(\mathrm{kg})\end{array}$ & $\begin{array}{c}\text { GP2 }(<150 \mu \mathrm{m}) \\
(\mathrm{kg})\end{array}$ & $\begin{array}{c}\text { Cement } \\
\text { replacement } \\
(\%)\end{array}$ & $\begin{array}{c}\text { Fine } \\
\text { Aggregate } \\
(\mathrm{kg})\end{array}$ & $\begin{array}{c}\text { Water } \\
(\mathrm{kg})\end{array}$ \\
\hline Control & 600 & - & - & 0 & 630 & 240 \\
\hline GP1-20 & 480 & 120 & - & 20 & 630 & 240 \\
\hline GP1-40 & 360 & 240 & - & 40 & 630 & 240 \\
\hline GP1-60 & 240 & 360 & - & 60 & 630 & 240 \\
\hline GP1-80 & 120 & 480 & - & 80 & 630 & 240 \\
\hline GP2-20 & 480 & - & 120 & 20 & 630 & 240 \\
\hline GP2-40 & 360 & - & 240 & 40 & 630 & 240 \\
\hline
\end{tabular}

\subsection{SPECIMENS}

Concrete cylinders of dimension $100 \mathrm{~mm}$ (diameter) and $200 \mathrm{~mm}$ (height) were prepared in accordance with AS 1012.8.1. Cylindrical moulds were filled in two approximate equal layers and compaction was done by rodding 25 strokes per layer. Concrete cylinders were cured in a moist room at more than $95 \%$ relative humidity and at a temperature of $23 \pm 2 \mathrm{C}$ for $24 \mathrm{~h}$, and then demolded, identified and immersed in limewater bath until testing time. This process of curing is complaint with the Australian standard AS 1012. 


\section{RESULTS \& DISCUSSIONS}

\subsection{WORKABILITY (AS 1012.3.1)}

The slump of all the mixes modified with the two glass powders GP1 \& GP2 compared with the reference mix is shown in the Figure 1. It is evident from the Figure 1 that the slump of the mix increases with glass powder replacement up to certain percentage (40\%-GP1 \& $60 \%$-GP 2 ) of glass powder substitution irrespective of the glass powder used compared to the reference mix. The trend of slump is similar in both the glass powders, after an initial increase at $20 \%$ replacement there is a decline in the slump. This pattern of initial increase and then decrease in the workability is reported by the previous studies by Sharifi et al. (2015). All the mixes regardless of the GP replaced exhibited slump values greater than the reference with the exception of mix GP1 at $80 \%$ replacement. The mix with GP2 at $20 \%$ substitution recorded the highest value of the slump which was approximately three times the slump of reference mix.

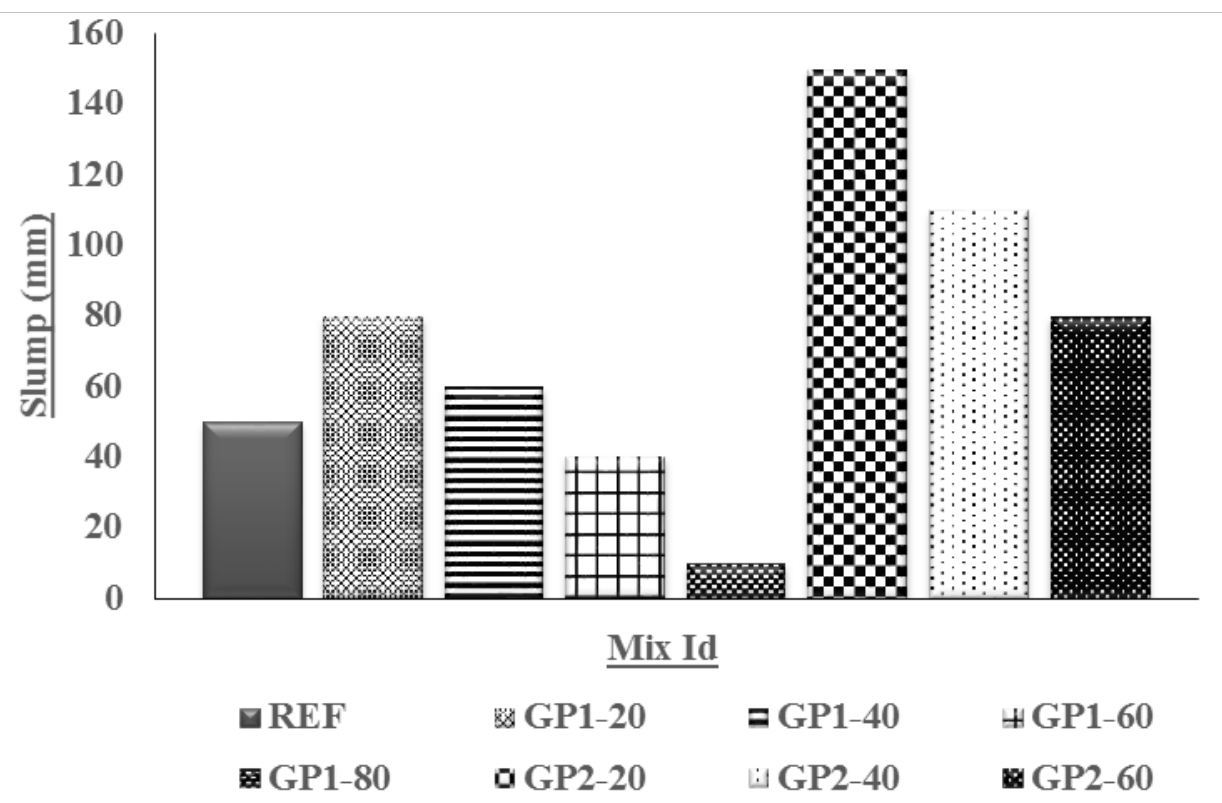

Figure 1 Workability of mixes

\subsection{HARDENED DENSITY (AS 1012.12)}

The densities of all the mixes in hardened state are depicted in Figure 2. The densities of the mixtures modified with the GP1 \& GP2 decreased compared to the reference mix, this reduction is proportional to the substitution percentage. $80 \%$ replacement yielded the least density out of all the modified mixes with a decreasing value of about $16 \%$. Stage two mixes resulted in a maximum reduction of $11 \%$ at $60 \%$ substitution level. Comparing the density values taken at both the intervals, it is noted that the 28-day densities of all the mixes was greater than the 7day with an exception of mix GP1-80. This characteristic of reduction in the density can be effectively used where there is a need of light weight concreting. 


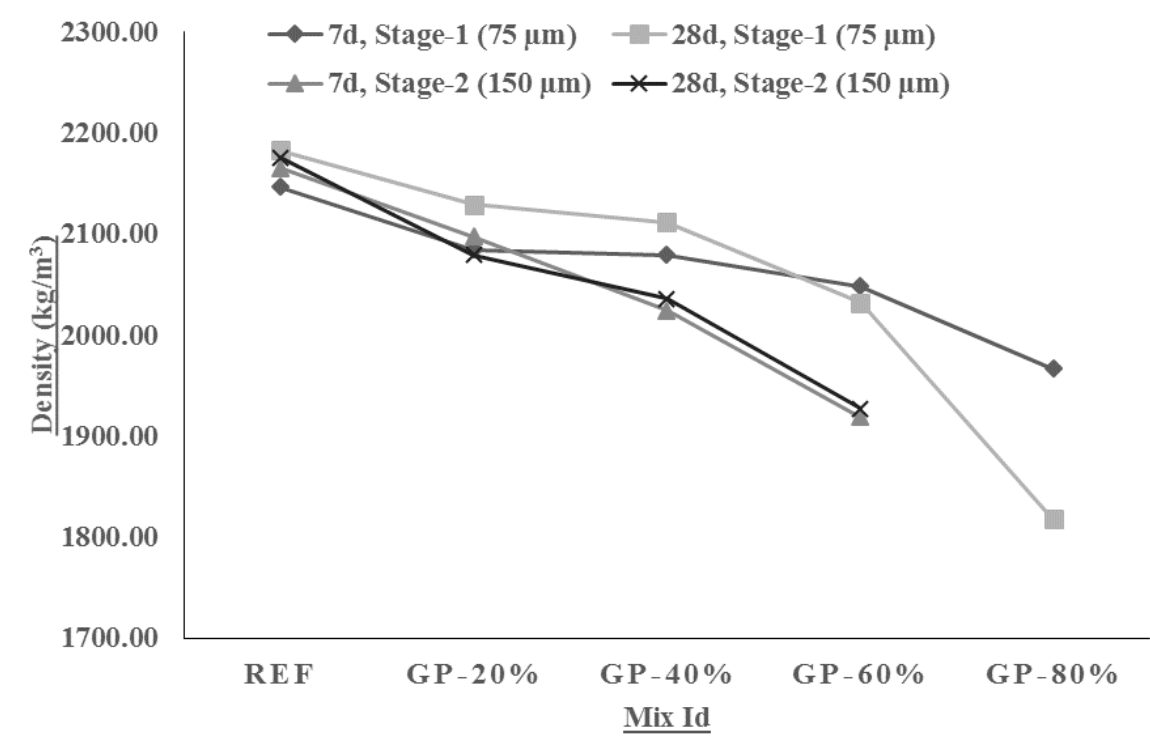

Figure 2 Density of mixes

\subsection{COMPRESSIVE STRENGTH \& STRENGTH ACTIVITY INDEX (AS 1012.9)}

The compressive strength test results of all the concrete mixes at 7,28 and 91 day curing ages are shown in Figure 3. There is a linear decrease in the strength regardless of the glass powder employed, $80 \%$ replacement yielded the lowest strength which was less than $10 \%$ of the reference at 28 days. As stated earlier, sine the pozzolanic activity of the GP is inversely proportional to the size, the performance of GP1 is consistently better than GP2 throughout the replacement levels. The decrease in compressive strength with the addition of GP is not necessarily a poor result as the $20 \%$ replacement resulted in a concrete strength $50 \mathrm{MPa}$. Although this is less than the control it is still strong. This allows for $20 \%$ less cement to be used in cases where $50 \mathrm{MPa}$ is the target strength. At $20 \%$ substitution, both the glass powders GP1 and GP2 exhibited almost similar strengths at respective curing ages. These outcomes are in agreement with the past studies reported in the literature wherein the optimum replacement content was $30 \%$ owing to the shortage of $\mathrm{CH}$ (Calcium Hydroxide) which is essential for the pozzolanic reaction for producing secondary C-S-H (Calcium Silicate Hydrate) (Du and Tan, 2017).

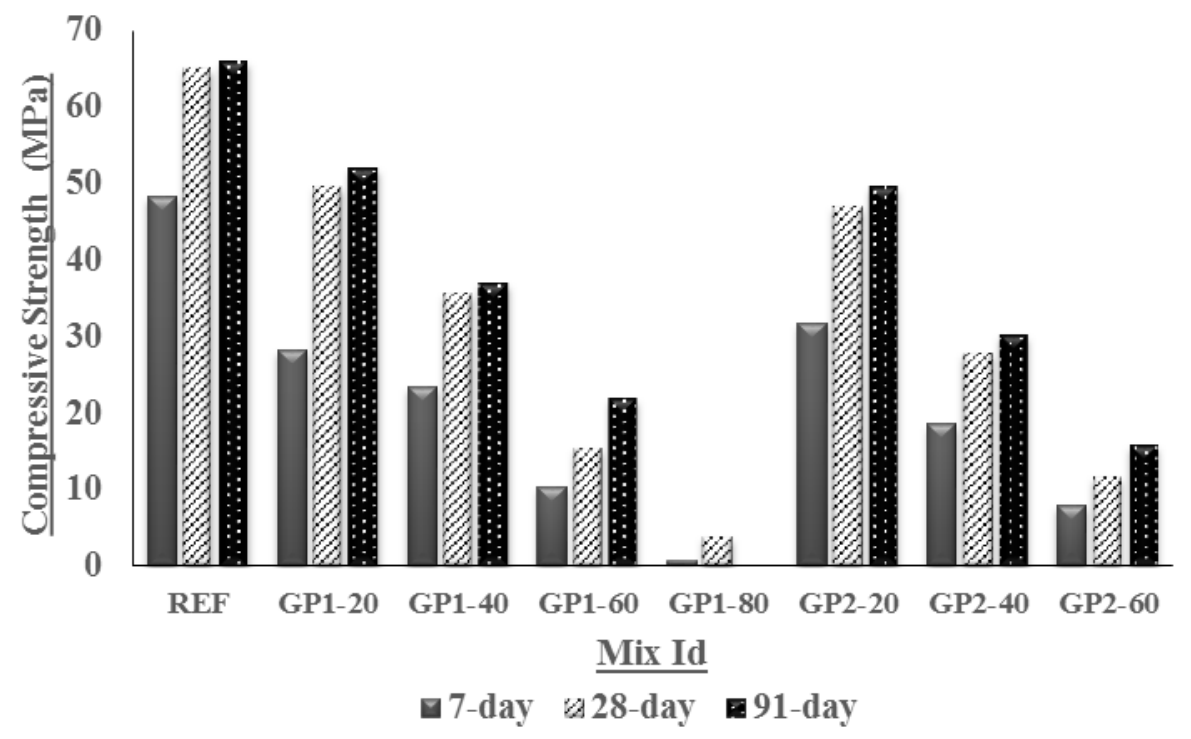

Figure 3 Compressive strength of mixes 
The pozzolanic performance of GP may be estimated with the Strength Activity Index (SAI), which is the ratio between strength of mortar containing GP and strength of equivalent reference mortar at the same age. The strength activity indexes of all the GP modified mixes is illustrated in the Figure 4. The best SAI was obtained at 20\% replacement in both the GP's and the value decreased with the increasing replacement percentage in all modified mixes. The SAI values of GP1-20 are $76 \%$ and $79 \%$ at 28 and 91 days respectively. Since the SAI of the mix GP1-20 is greater than $75 \%$, it can be treated as a pozzolan according to the standard ASTM C618-05, (2005). The mix GP2-20 was also not far behind as it showed a SAI values of $73 \%$ and $75 \%$ at 28 and 91 days respectively. Shi et al. (2005) reported similar results with a 20\% GP replacement and the SAI obtained was around $74 \%$ at 28 days. These results indicate that the maximum pozzolanic activity of the glass powders used in the current research was obtained at $20 \%$ replacement.

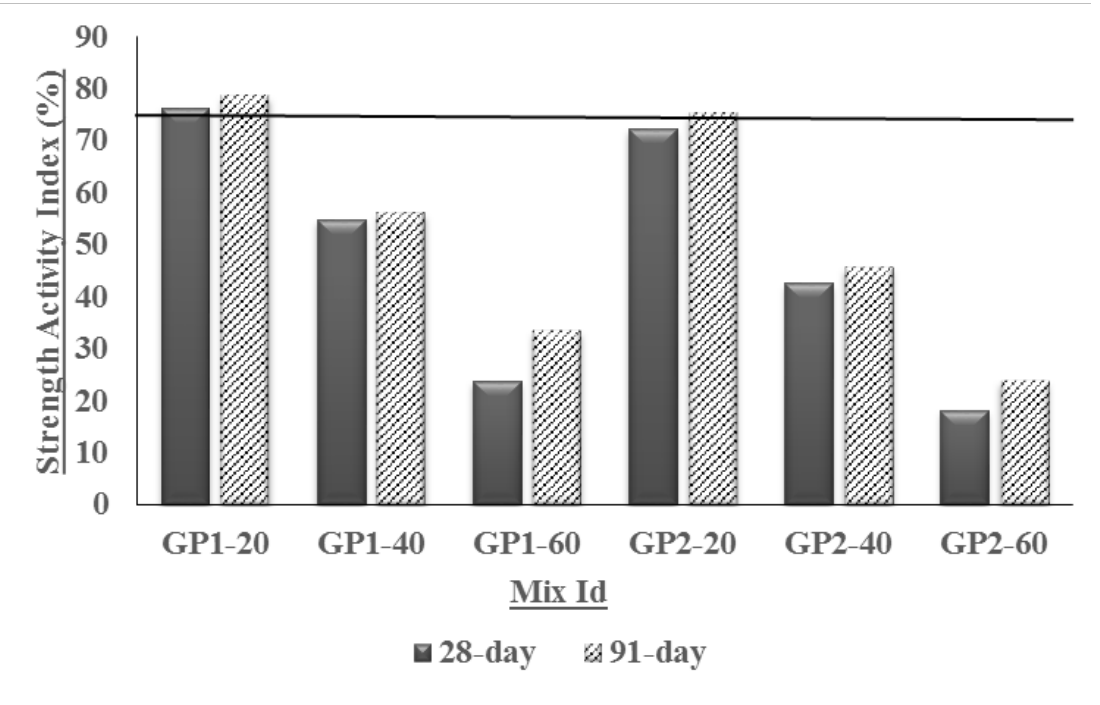

Figure 4 Strength activity index at 28 and 91 days

\subsection{TENSILE STRENGTH (AS 1012.10)}

Figure 5 provides the results of 7 and 28 day tensile strength of GP2 at various substitution levels and compares it with the reference mix. Similar to the compressive strength, there is a linear decrease in the tensile strength with the increase in replacement percentage. Out of all the glass powder modified mixes tested, $20 \%$ replacement gave the best results.

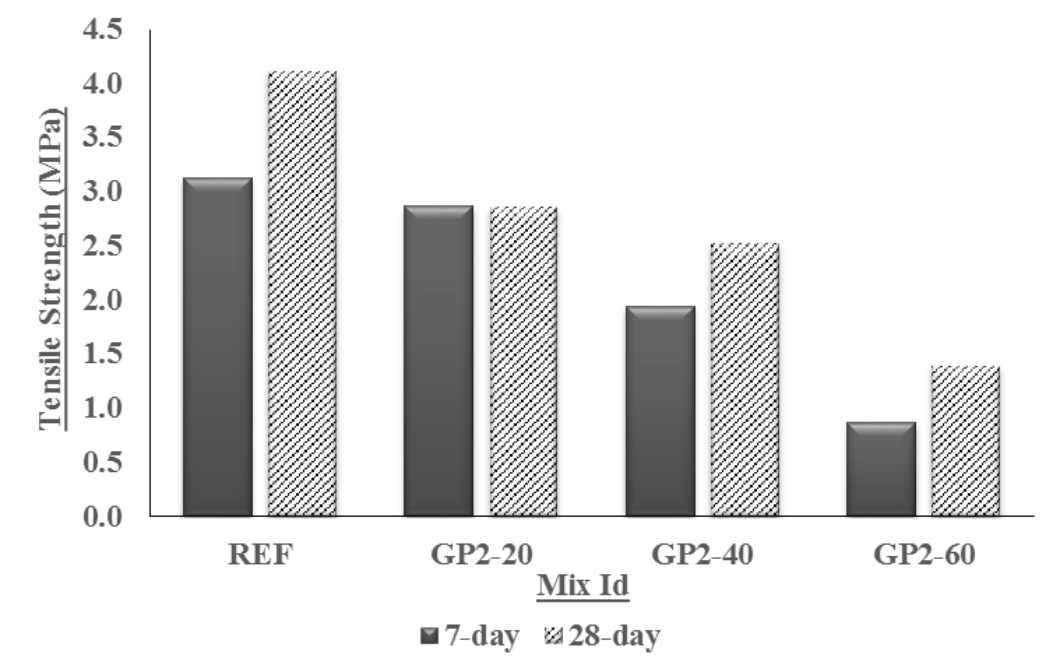

Figure 5 Tensile strength of mixes 


\section{CONCLUSION}

This study reported experimental results on the use of two recycled glass powders, GP1 and GP2 as supplementary cementitious material in concrete. Unlike previous work, this study examined the effects of a higher GP replacement of up to $80 \%$. Based on the newly obtained results, the following conclusions can be drawn:

- Both the glass powders used in the study followed a similar pattern in workability, after an initial increase at $20 \%$ replacement the workability reduced at higher substitution levels;

- The hardened densities of the mixes modified with the GP1 and GP2 yielded lesser values compared to the reference conventional Portland cement indicating a possibility of using the glass powder for light weight structures;

- Apropos the compressive strength, GP1 at 20\% replacement outperformed other modified mixes, nonetheless the performance reduced at higher substitution levels and the strength values where almost similar to GP2;

- Both the glass powders, GP1 \& GP2 at 20\% substitution exhibited a SAI values greater than 75 at 91 days of curing and hence can be used as a pozzolanic cementitious material;

- Tensile strength followed a similar trend like compression and 20\% replacement was ideal for the glass powder under examination; and

- Since GP increased workability, further research could be done by decreasing water cement ratio so as to increase the compressive strength of the GP modified concrete.

\section{REFERENCES}

Arulrajah, A., M. M. Disfani, H. Haghighi, A. Mohammadinia and S. Horpibulsuk (2015). "Modulus of rupture evaluation of cement stabilized recycled glass/recycled concrete aggregate blends." Construction and Building Materials 84: 146-155.

ASTM C618-05 (2005). standard specification for coal fly ash and raw or calcined natural pozzolan for use in concrete. West Conshohocken, PA, ASTM International.

Du, H. and K. H. Tan (2013). "Use of waste glass as sand in mortar: Part II - Alkali-silica reaction and mitigation methods." Cement and Concrete Composites 35(1): 118-126.

Du, H. and K. H. Tan (2014). "Effect of particle size on alkali-silica reaction in recycled glass mortars." Construction and Building Materials 66: 275-285.

Du, H. and K. H. Tan (2015). "Transport Properties of Concrete with Glass Powder as Supplementary Cementitious Material." ACI Materials Journal 112(3).

Du, H. and K. H. Tan (2017). "Properties of high volume glass powder concrete." Cement and Concrete Composites 75: 22-29.

Duchesne, J. and M. Bérubé (1994). "The effectiveness of supplementary cementing materials in suppressing expansion due to ASR: another look at the reaction mechanisms part 2: pore solution chemistry." Cement and Concrete Research 24(2): 221-230.

Etris, S., Y. Fiorini, K. Lieb, I. Moore, A. Batik and C. Johnston (1974). "Waste glass as coarse aggregate for concrete." Journal of Testing \& Evaluation 2.

Farshad, R., A. M, M. Hamed and F. Gregor (2010). "Investigating the Alkali-Silica Reaction of Recycled Glass Aggregates in Concrete Materials." JOURNAL OF MATERIALS IN CIVIL ENGINEERING 22(12): 1201-1208.

Gopalakrishnan, R. and D. Govindarajan (2011). "Compressive Strength and Electron Paramagnetic Resonance Studies on Waste Glass Admixtured Cement." New Journal of Glass and Ceramics 01(03): 119-124. 
Jain, J. A. and N. Neithalath (2010). "Chloride transport in fly ash and glass powder modified concretes - Influence of test methods on microstructure." Cement and Concrete Composites 32(2): 148-156.

Kamali, M. and A. Ghahremaninezhad (2016). "An investigation into the hydration and microstructure of cement pastes modified with glass powders." Construction and Building Materials 112: 915924.

Liu, F., L.-y. Meng, G.-F. Ning and L.-J. Li (2015). "Fatigue performance of rubber-modified recycled aggregate concrete (RRAC) for pavement." Construction and Building Materials 95: 207-217.

Lopez-Gayarre, F., R. B. Vinuela, M. Serrano-López and C. Lopez-Colina (2015). "Influence of the water variation on the mechanical properties of concrete manufactured with recycled mixed aggregates for pre-stressed components." Construction and Building Materials 94: 844-850.

Lotfi, S., M. Eggimann, E. Wagner, R. Mroz and J. Deja (2015). "Performance of recycled aggregate concrete based on a new concrete recycling technology." Construction and Building Materials 95 : 243-256.

Mehta, P. K. (2002). "Greening of the concrete industry for sustainable development." Concrete international: 23-28.

Nassar, R.-U.-D. and P. Soroushian (2012). Green and durable mortar produced with milled waste glass. Concrete Research. 64: 605-615.

Omran, A. and A. Tagnit-Hamou (2016). "Performance of glass-powder concrete in field applications." Construction and Building Materials 109: 84-95.

Ramlochan, T., M. Thomas and K. A. Gruber (2000). "The effect of metakaolin on alkali-silica reaction in concrete." Cement and Concrete Research 30(3): 339-344.

Saccani, A. and M. C. Bignozzi (2010). "ASR expansion behavior of recycled glass fine aggregates in concrete." Cement and Concrete Research 40(4): 531-536.

Shang, H.-s., T.-j. Zhao and W.-q. Cao (2015). "Bond behavior between steel bar and recycled aggregate concrete after freeze-thaw cycles." Cold Regions Science and Technology 118: 38-44.

Shao, Y., T. Lefort, S. Moras and D. Rodriguez (2000). "Studies on concrete containing ground waste glass." Cement and Concrete Research 30(1): 91-100.

Sharifi, Y., I. Afshoon and Z. Firoozjaie (2015). "Fresh Properties of Self-Compacting Concrete Containing Ground Waste Glass Microparticles as Cementing Material." Journal of Advanced Concrete Technology 13(2): 50-66.

Shayan, A. and A. Xu (2004). "Value-added utilisation of waste glass in concrete." Cement and Concrete Research 34(1): 81-89.

Shi, C., Y. Wu, C. Riefler and H. Wang (2005). "Characteristics and pozzolanic reactivity of glass powders." Cement and Concrete Research 35(5): 987-993.

Silva, R., R. Neves, J. De Brito and R. Dhir (2015). "Carbonation behaviour of recycled aggregate concrete." Cement and Concrete Composites 62: 22-32.

Taha, B. and G. Nounu (2008). "Using lithium nitrate and pozzolanic glass powder in concrete as ASR suppressors." Cement and Concrete Composites 30(6): 497-505.

Topcu, İ. B. and M. Canbaz (2004). "Properties of concrete containing waste glass." Cement and Concrete Research 34(2): 267-274.

US GEOLOGICAL SURVEY 2017.

Wang, Z., C. Shi and J. Song (2009). "Effect of glass powder on chloride ion transport and alkaliaggregate reaction expansion of lightweight aggregate concrete." Journal of Wuhan University of Technology-Mater. Sci. Ed. 24(2): 312-317. 